\title{
14
}

\section{Typecasting in the Recruitment of Full Professors}

\author{
Sara Levander, Eva Forsberg, Sverker Lindblad, \\ and Gustaf J. Bjurhammer
}

\section{Introduction}

The recruitment of full professors is critical for the formation of academia. Usually, it is closely connected to the fulfillments of the universities' core missions, and thus, has long-term effects on the future academic profile of departments and higher education institutions (HEI). The latter holds true both in terms of the profile of the professorship per se, and insofar as professors commonly are involved in the strategic recruitment work and the recruitment processes of other academic staff members at the department (Klawitter, 2015). Thus, the recruitment of professors impacts not only the HEI and department, but also individual academic's careers. Hence, it is a political and highly symbolic act (Musselin, 2010).

S. Levander $(\bowtie) \bullet$ E. Forsberg $\bullet$ G. J. Bjurhammer Department of Education, Uppsala University, Uppsala, Sweden e-mail: sara.levander@edu.uu.se

S. Lindblad

University of Gothenburg, Gothenburg, Sweden 
However, the professorship is paramount not only for the prosperity of the HEIs, but especially so for the establishment, development and communication of the discipline. In a Humboldtian sense the professorship unites the two functions research and education, and is therefore a fundamental part of the disciplinary building (Hofstetter \& Schneuwly, 2002). In fact, as part of a discipline's self-perception the professorship may be considered an integrated part of the discipline itself (Lindberg, 2006/2007). Although disciplinary teaching and research traditionally have been the core activities incumbent on the professoriate, the academic profession has undergone profound changes during the last decades, and academic work is no longer solely about teaching and research (Fumasoli et al., 2015). Consequently, expectations put on the professoriate have shifted over the years. This is also reflected in job advertisements for vacant professorships: in addition to teaching and research, candidates are progressively expected to meet additional criteria to be appointed as professors (e.g. the ability to attract external funding, to cooperate within and outside academia, to conduct international work, and to occupy a specialized academic profile) (Klawitter, 2015).

Since the professorship is a particularly interesting index for the emergence and re/formation of a disciplinary field (see e.g. Hofstetter \& Schneuwly, 2002), the gatekeeping practices involved in the appointment of the professorship are of utmost importance to study. This is the task that this chapter takes on. We are especially interested in the conditions that frame these gatekeeping practices. Here we focus on one of the initial and formal aspects of the typecasting process (Hamann \& Beljean, 2019), that is, the gatekeeping practice were candidates are valued and evaluated based on how well they fit a certain type, or academic profile, as outlined in job advertisements. Job advertisements are the result of "a two-part labor supply construction process" (Musselin, 2010, p. 56). During this phase in the process, the breadth of the field and how specialized or vague the job advertisement should be is determined. This step helps to organize and guides the subsequent matchmaking process, in particular the legitimacy of assessments and decisions made by peer reviewers and committees (Hamann \& Beljean, 2019; Musselin, 2010). We use a few cases to illustrate how the intellectual and social organization of the field of education science(s) [pedagogiska kunskapsområdet] 
is manifested in the recruitment of full professors. By means of the advertisements, categories indicating what the candidates are expected to do, within which area of expertise, and so on are outlined. Thus, we may expect that boundaries for the disciplines of the education science(s) and their disciples are drawn up, negotiated, and established. The field of education is especially interesting for the study of the intellectual and social organization of a field since it is - in comparison with some other disciplinary fields within the social sciences-a highly heterogeneous field (Forsberg \& Sundberg, 2018) with diversified job tasks.

\section{The Field of Educational Science(s)}

In the recruitment of professors in education, the ways in which the educational science(s) are organized and carried out are important aspects and a complex matter in several respects. A way to capture this complexity is presented by Hofstetter and Schneuwly (2002) who situate education as a field of study with a threefold basis with different interests - in relation to the academy and scientific demands, in relation to the teaching profession, and in relation to society and expectations on educational systems in terms of economy, culture, and so on-often transmitted by policy-making. These different interests often produce dilemmas for the field of educational sciences and by that also varying expectations on professors in this field.

Educational ideas and reasoning have a long history in academiamostly in Philosophy. But as a distinct part in the system of higher education and research, educational science(s) has a shorter life, often related to the emergence of the social sciences and welfare state organization. Internationally the study of education can be characterized by three clusters of knowledge traditions; academic knowledge traditions, practical knowledge traditions and integrated knowledge traditions (Whitty \& Furlong, 2017).

Academic knowledge traditions are depicted in terms of 'singulars' and 'regions'. Singulars have their own intellectual field of texts, practices, and rules of entry. They are protected by strong boundaries and hierarchies. In some singulars, for example mathematics, the knowledge 
structure is relatively unified and hierarchical, and they have well-agreed procedures for testing new knowledge. Other singulars, for example sociology, have a more eclectic knowledge structure in which different subgroups adopt different methodological and epistemological assumptions. Regions on the other hand, are made up of a number of singulars that are re-contextualized into larger units, and they operate both in the intellectual field of disciplines and in a field of practice. Despite the fact that they consist of different sub-disciplines they function to some degree as a single discipline, because they are held together by their engagement with a specific field of practice.

Practical knowledge traditions are closely linked to the world of practice. They share a common interest for professional knowledge and enhancing the educational practice, rather than developing disciplinebased knowledge. Some of them have a long history, such as The normal college tradition that dates back to the end of the 17 th century, while others, such as The networked professional knowledge tradition, stress the importance of treating practitioners as the main source of the creation of professional knowledge. Other examples of practical knowledge traditions are Education as a Generic, that is, performance-oriented movements to enhance generic competences and standards of practice, Personal liberal education and Craft knowledge.

Integrated knowledge traditions are neither primarily academic nor primarily practical in their genesis, and they do not consider the links between theory and practice as something to be achieved. Rather, these links are considered as central to the process of knowledge production itself. These traditions are limited in number, and their status in academia is debatable. Examples of integrated traditions in the study of Education are Pedagogija (Latvia), practitioner enquiry/action research, clinical practice, and learning sciences. The necessity of searching for the development of integrated traditions is pointed out in the literature; to create powerful professional knowledge it is needed to bring together disciplinary knowledge and other external knowledge with professionals' reflective practice and practical theorizing. (Whitty \& Furlong, 2017)

Although there are commonalities independently of national context, the emphasis and impact of these traditions differ somewhat across nations depending on local demands and prerequisites. The institutional 
organization also differs across nations (Whitty \& Furlong, 2017). Organizationally, educational science(s) may be at home in the universities, but it may also proceed 'in between' universities and educational systems (Keiner, 2019).

While some countries have a unified institutional structure, that is, the university, others make formal divisions between different types of universities. Yet others have a highly fragmented institutional structure including distinct specialist institutions based on different knowledge traditions.

In Sweden, educational research has to a very large extent been institutionally organized in the discipline of Pedagogik (Rosengren \& Öhngren, 1997). Today the organization of the field looks different. We find a shifting basis for educational research in terms of relevance: first in relation to science, then to policy-making, and then over to professional practice and efficiency. A point of departure for describing the development of educational science(s) in Sweden is the making of professorships in education as a science (Pedagogik) and by that Education as a scientific discipline. After a long debate, Pedagogik was introduced in 1908 at Uppsala University and a few years later at the University of Lund. An important reason for this introduction was to create a scientific basis in the training of teachers based on, for example philosophy (why education?) and psychology (how to make students learn?). In terms of relevance, the important point was that studies in education had a scientific ground. Since then, demands of relevance have been of vital concern in changes of education as a discipline in Sweden. Particularly scientific relevance has been a dominating demand (Foss Lindblad \& Lindblad, 2016). This was later followed by education science as a basis for extensive reforms of primary and secondary education after World War II, and thus a matter of policy relevance (see the Research Council evaluation of educational sciences in 1995). However, this was combined with increasing demands for professional relevance. First in terms of application of scientific findings as in educational technology and in the making of a sectoral organization of educational research in the 1970 s, and later by a practical turn in the 1990 s with expansion of didactics and in the making of a clinical educational science, such as pedagogical work. To this fairly straightforward history of the educational science(s) in Sweden, education has 
increasingly been subject to other disciplines and to cross-disciplinary ambitions, as manifested in the turning of the Swedish Research Council resources for educational research (Benner, 2009). Several other disciplines, mostly within the social sciences and the humanities now receive around half of the resources for educational research from the research council (Foss Lindblad \& Lindblad, 2016). This is accompanied by a growing number of academics working in the system of higher education and research having a $\mathrm{PhD}$ based on educational research. Thus, the competition for research funds is even fiercer.

\section{Recruitment Procedures-A National Context}

Each national higher education system has its own specific procedures for recruiting professors, and the position entails different duties and rights, expectations and accountabilities depending on the particular system. Although there national distinctions and varying details of the pathway to the professorship across nations and HEIs (Angermuller, 2017), the use of peer review is customary and a common denominator is the earning of the PhD as an initial step (Hamann, 2019). As illustrated in Chap. 13 in this volume, this is true also in Sweden.

Until 1993, the majority of professors in Sweden were appointed as chairs or with authorization [fullmaktsprofessorer]. These types of professorships meant a fairly high level of autonomy, and a very high level of employment security. In contrast to today when professors are appointed by the university, they were appointed by the government. They were also leaders of the department and responsible for the discipline (e.g. Pedagogik). However, in 1977, when people other than the professors could be elected to head of department, the professors' hold over the department was diminished. In part, this was related to the general perception that the professoriate was an overly privileged group of academics. During the 1990s and onwards, the system has successively been transformed into one where department heads primarily serve as administrators and decision-makers. This transformation was part of what is often regarded neoliberal reforms of higher education, with changes in governance and reduced collegial decision-making, which led to competitions between universities and departments over financial resources and 
students. In turn, this has had important implications for positions and tasks for professors. In addition to changed power relations, the professors' duties nowadays primarily encompass research, teaching and, increasingly so, public outreach. Due to altered funding regimes, a good deal of the professors' time is currently dedicated to attract research funding.

The recruitment process is regulated by national law and ordinance, and the use of peer review in academic recruitment has been an institutionally established practice since 1876 . While the government stipulates the criteria of eligibility and assessment, most higher education institutions have, as in many other countries, developed supplementary local guidelines and regulations to rule these processes. The eligibility for appointment to full professor in Sweden is the demonstration of both research and teaching expertise, and as much attention shall be given to the assessment of teaching expertise as to research expertise (SFS, 1993:100/2010:1064). In the discipline of education (pedagogik), the double competence was often stressed as a criterion of eligibility in the recruitment of professors during the twentieth century (Lindberg, 2006/2007). This meant candidates had to have qualifications equivalent to a double docent competence-double in the sense of being competent in at least two distinctly different scientific areas-to be considered eligible. Education was regarded such a wide and comprehensive discipline that it required research experience from at least two distinct disciplinary sub-areas to take on the responsibility of representing such a discipline.

The entire recruitment process involves several steps. First (1), there is the initial decision to recruit, usually made by the faculty board. This decision is context dependent, for example, the academic profile of the $\mathrm{HEI}$, and involves negotiations at the faculty and departmental level. Subsequently (2), the vacant position is publicly advertised. The advertisement is essential for the entire process since it conveys desirable competences stipulated by the HEI and thus guides the subsequent steps. Third (3), applicants apply for the position, which is subsequently followed by (4) the selection of external peers by the recruitment board. Customarily two reviewers, external to the HEI in question, are appointed. The reviewers are assigned the task to assess the candidates' qualifications in terms of teaching expertise, research expertise, and expertise in 
academic leadership. Traditionally, the external reviewers are selected based on their expert knowledge in the area or subject of the current position. However, due to the expansion of positions and review tasks during the last decades, today, reviewers are increasingly faced with the task to assess candidates who are not in the same research field as themselves. Rather, it is becoming more and more common that reviewers are expected to assess candidates in fields that are "overlapping", "related" or "adjacent" to the field of the reviewer (Kaltenbrunner \& de Rijcke, 2019, p. 873). In a heterogeneous field such as the educational sciences, this is even more so. The reviewers' evaluation reports (5) form the basis of the recruitment board's nomination of whom to hire (6). The final decision (7), for professorships, lies with the Vice-Chancellor. Figure 14.1 illustrates this process, and highlights the step under scrutiny here.

The recruitment process lies in the intersection between institutional desires and academic values, and each step in the process involves negotiations and decisions on managerial and/or collegial levels. These decisions are made by distinct actors, who all serve as gatekeepers of different kinds and at different stages in the process. For instance, before the advertisement is published heads of departments, deans, members of the recruitment boards, and staff from human resources departments have been involved in decisions on recruitment, profile, desired qualifications etc.

\section{Typecasting in the Recruitment of Full Professors}

The analysis is framed by Hamann and Beljean's (2019) concept of typecasting in recruitment of academics. The concept is most commonly associated with typecasting processes in the art, theatre, and film

\begin{tabular}{|cccc|c|c|c|}
$\begin{array}{c}\text { Context/ } \\
\text { institutional } \\
\text { negotiation }\end{array}$ & $\begin{array}{c}\text { Candidates' } \\
\text { application files }\end{array}$ & $\begin{array}{c}\text { Reviewers' } \\
\text { evaluation } \\
\text { reports }\end{array}$ & Final decision \\
\hline 1 & 2 & 3 & Selection of & Nomination of
\end{tabular}

Fig. 14.1 The process of recruiting full professors in Sweden 
industry, where it generally refers to the process when an actor becomes strongly identified with a specific character, or characters having similar traits. Among actors, typecasting often has negative connotations as it indicates an actor's limitation or lack of talent (Wojcik, 2003). In this chapter, the concept is based on research on typecasting in labor markets (Zuckerman, 2005), and refers, as stated, to the gatekeeping practice were candidates are valued and evaluated based on how well they fit a certain type outlined in the advertisement, that is, the preferred academic profile. It is part of controlling access to desirable positions in a specific scientific field. In this process of sorting out the wheat from the chaff, candidates are "screened according to and matched with specific categories that are considered relevant for the job at hand" (Hamann \& Beljean, 2019 , p. 15). The job advertisements mobilize these categories and serve as a backdrop for the subsequent match-making process. To the extent that reviewers explicitly refer to documents other than the application files, they typically do so in relation to the advertisement. In the matchmaking process, the reviewers are highly dependent on whether the advertisements are 'open' and vaguely written or if they are specified and precise (Musselin, 2010). The former strategy opens up the field of candidates to elicit and choose the best one, while the latter targets the population of candidates.

The advertisements used here are derived from recruitment processes of full professors in the field of educational sciences at three higher education institutions (HEIs) in Sweden: two universities (University I and II) and one university college (University College). All positions issued during the period 2011-2018 are included, which in total gives seven distinct positions - one at the university college, two and four at the two universities respectively_-in Pedagogical work, Child and youth studies, Education, Sociology of education, Education focusing on special needs education, and Curriculum studies focusing on the Swedish language. While the entire corpus includes job advertisements, application files, external reviewers' evaluation reports, decision protocols and policy documents guiding the process, the advertisements constitute our prime source of data. Although there are minor divergences in terms of structure and headings, scope and level of detail, the advertisements follow a similar structure and cover a similar content. In contrast to the 
advertisements studied by Hamann and Beljean (2019), the advertisements by far exceed more than a few sentences; they range from two to up to four pages.

\section{The Intellectual and Social Organization of Educational Science(s)}

When we now turn to the typecasting process in the recruitment of professors, we could expect that the field no longer has a basis in one single discipline, and that there are different ways to state what is expected from a professor. The professorships in our sample encompass both general (Education, Pedagogical work, Child and youth studies, Sociology of education) and specialized professorships (Curriculum studies focusing on the Swedish language, Education focusing on special needs education). Some of these are differentiations from Education, some also have roots in other subjects or disciplines, and yet another is a specialization within Education.

\section{The Emergence of a Heterogeneous Field}

Our cases show that the field is characterized by some common features as well as by variation. We can see several of the knowledge traditions pointed out by Whitty and Furlong (2017) reflected in the professorships, and their interweaving with the social world and the professional field of reference (Hofstetter \& Schneuwly, 2002) differ. In essence, there is a dominant interest in the teaching profession and teacher education. In a majority of advertisements this is manifested in terms of "particularly there will be job tasks that focuses teachers' professional knowledge", "the research shall meet the challenges in education of special teachers in preschool and school" or "...practical experience from preschool" being considered an additional qualification for the position. Focus is on the formal school system, particularly preschool and school, and again on teacher education. In this sense, we see similarities to the practical knowledge traditions identified in prior research (Whitty \& Furlong, 2017). In 
spite of this common trait, and despite our small sample, our cases also reflect the heterogeneity pointed out in the literature (Hofstetter \& Schneuwly, 2002; Forsberg \& Sundberg, 2018). Although there is an emphasis in interest towards the formal school system, taken together, the advertisements demonstrate an interest in the entire school system (preschool to higher education) as well as other professional practices and everyday life. In part, this is of course related to the fact that the sample comprises positions in disciplines with a long academic tradition, as well as more recently established subjects with a special focus. Hence, the objects of knowledge vary from children's and young peoples' literacy or assessment of teaching content, to the philosophy and politics of education, socialization, and Bildung. While the focus on certain substantive educational topics such as early years and assessment in some of the professorships would indicate a position as a 'region', statements like "[ the discipline] is based on more general traditions in sociology and historical science" could be an indicator of a 'singular' tradition (Whitty \& Furlong, 2017). The absence of such specifications (as in e.g. Education) may also imply a 'singular' position.

\section{The Selection of Peers}

The heterogeneity of the field is reflected also in the selection of peer reviewers. Around half of them are professors in Education, the remaining in Pedagogical work, Subject didactics, Sociology, History of economics, Special needs education, Science of literature with focus didactics and Bilingualism with focus on Swedish as second language. This would, on the one hand, suggest the field is a multidisciplinary based field, or a region (see Whitty \& Furlong, 2017). On the other hand, the fact that professors in Education (all of which holds a $\mathrm{PhD}$ in Education) are selected to review candidates for positions other than in Education would rather indicate that Education as a discipline is understood to encompass the other (sub)disciplines, and thereby being a singular (see Whitty \& Furlong, 2017). Indeed, it might simply imply that there is a lack of reviewers in the specific subject or discipline at hand, and that reviewers in disciplines adjacent or overlapping to the field of the reviewer are engaged (see Kaltenbrunner \& de Rijcke, 2019). 


\section{The Mobilization of Job Categories}

The mobilization of job categories and stipulation of desired qualifications is a prerequisite for the reviewers to be able to make the right fit. In one sense, the job categories are similar across cases: teaching, research, and collaboration. These categories encompass different and more or less specific duties and responsibilities. Similar to previous findings (Klawitter, 2015) it is clear that the contemporary professor not only is expected to teach and conduct research, but also to perform a range of distinct job tasks. These involve various administrative responsibilities, academic leadership including conflict managing, relational work such as internal collaboration, public outreach, service, as well as attracting research funding.

The emphasis of job categories differs, however, depending on type of professorship and discipline. Teaching and research are dominant in all advertisements, even if the establishment and development of these activities are in focus for the more specialized professorships or professorships tied to the establishment of new subjects on third cycle. A noticeable difference is that public outreach or collaboration within academia is hardly mentioned in the professorships from University II, while this is a highly stressed category in the other advertisements, particularly so for the professorships in Pedagogical work. This could be because Pedagogical work is a relatively new, explicitly practice oriented and interdisciplinary subject that is dependent on collaboration across disciplinary boundaries inside and outside academia to be able to develop. One of the professorships in Pedagogical work was, as mentioned, tied to the establishment of Pedagogical work as a third cycle subject which might have accentuated this need for cooperation in the building-up phase even more. Such an inference is contradicted however, by the fact that the professorship in Education focusing on special needs education at the University II also was tied to the establishment of a new subject on third cycle, which rather would suggest these differences vary by type of HEI. The fact that collaboration is not explicitly accentuated as a job task in the advertisements at University II might seem odd at first, but one interpretation could be that this is regarded such an obvious part of the professor's duties that it does not need explicit articulation. The teaching-research nexus is treated in a similar way; it is an explicitly and highly stressed job task at the 
University College and University I, but not at all mentioned as a duty for the professor at University II, albeit stipulated as a criterion of assessment.

Moreover, the job descriptions show divergences in level of detail. To varying extent, we find reflections of the two distinct strategies by which advertisements can be constructed (see Musselin, 2010). Most detailed descriptions are found at the University College, and least at University II. That is, most detailed descriptions are found at the youngest HEI, where the professorship is tied to the establishment of a new subject on third cycle level. Least detailed are the two general professorships from the oldest university (University II). And again, a more general difference between the advertisements from University II and the others is that they contain rather short standardized formulations in respect of job tasks. This may reinforce the assumption that the process of recruiting full professors is an established practice at this university in which there is consensus on what to expect from a holder of this position. It also implies that more newly established disciplines want to guide both candidates and peer reviewers more in what they desire.

Taken together, these findings suggest that type of HEI is highly influential on the design and content of the advertisements.

\section{The Intersection Between Institutional Demands and Scientific Values}

Although all advertisements contain articulations like "contribute to develop the subject child and youth studies" focus lie primarily on departmental job tasks and duties such as "have a key role in the further development of cooperation between various specializations at the department and thereby regenerate and reinforce scientific profiling" or "[c]ontribute to the establishment of a premeditated graduate school". At University II, the departmental expectations are more pronounced insofar as they expect the future candidate to undertake administrative and managerial duties such as "head of department or director of studies".

The departmental expectations may also be perceived in terms of whether the professor is expected to primarily build or develop an activity or practice. In this regard, there is a slight distinction between the 
professorships that are tied to the establishment of a new subject on third cycle and the other professorships. Unsurprisingly, for the former there is an emphasis on building, even if development also is stated. While it is most emphasized and elaborated for the professorship tied to the establishment of the subject Pedagogical work, it is briefly stated for the professorship in Education focusing on special needs in that the professor "will play an important part in the establishment and development of the subject area”.

\section{Eliminatory Criteria, Signs and Retrospective Judgments}

Prior research has shown that reviewers look for eliminatory criteria (criteria of eligibility) and positive signs (criteria of assessment) when making their assessments (see Musselin, 2002). For this match-making process, the advertisements serve as a backdrop and are of great significance for the reviewers and their work in finding the right candidate. A common eliminatory criterion stipulated in the advertisements is "demonstrated" or "documented" scientific and teaching expertise, in accordance with the higher education ordinance. Here too, there are differences in scope and level of detail, depending on subject/discipline and/or HEI. Most advertisements elaborate what they mean by scientific and teaching expertise (and this vary somewhat), but one only refers to "the higher education ordinance" and "[the University's own appointment regulations]". Interestingly enough, while "independent research activities within [det barnpedagogiska forskningsfältet]" and "extensive and documented empirical research on children and preschool" are stipulated as eliminatory criteria for the professorship in Child and youth studies, none of the other advertisements stipulate knowledge in a specific field of research as an eliminatory criterion, and none stipulates a specific subject or discipline for the $\mathrm{PhD}$. Another interesting divergence is University II's specification of "personal qualities required to do the job satisfactorily" as an eliminatory criterion.

While subject or discipline is sparsely articulated in relation to eliminatory criteria, it is more emphasized as a positive sign. Experience from research in the same field as that of the position is to a varying degree 
stressed for all professorships. Other positive signs are the ability to attract research funding, to establish and develop a research environment, and to collaborate across disciplinary or institutional boundaries, as well as experience from successful doctoral supervision, experience from national and international research networks and international publication in high quality journals. As pointed out earlier, University II has quite short and "open" advertisements in terms of future job tasks. In terms of assessment criteria, the situation is reversed. They are relatively elaborated, albeit standardized across cases, and they include criteria for the assessment of administrative and management expertise. The latter includes for example "the capacity to manage operations and personnel, to make decisions, to take responsibility, and to motivate others and provide them with the prerequisites to efficiently achieve common goals". It also refers to " $[\mathrm{t}]$ he ability to coordinate the group and to help create commitment, participation, and job satisfaction, as well as the ability to manage conflicts". Common for all professorships is that both eliminatory criteria and signs are expected to be based on retrospective judgments. That is, the reviewer shall assess the candidates' prior achievements, rather than ability and potential to perform future activities.

\section{Conclusive Notes}

\section{Typecasting as a Device of Peer Review in the Formation of Education Science(s)}

In this chapter, we have studied one of the initial stages in the typecasting process in the recruitment of full professors in the field of education science(s). We have argued that job advertisements serve as a backdrop for the typecasting process in finding the right fit. Advertisements are the results of numerous collegial and managerial deliberations and negotiations at institutional and departmental levels. We have demonstrated the possibility to discern a re-/formation of a scientific field and a professorship by studying job advertisements. From the viewpoint of the knowledge traditions pointed out by Whitty and Furlong (2017), our findings suggest that the professorship of education science(s) in late modernity is 
tied to both practical knowledge traditions and academic knowledge traditions ('singulars' and 'regions'). However, even if we were able to discern indications of these traditions, and a varying intersection of them in some of the professorships, the indicators are divergent to some extent and manifest articulations in this respect are few. Documentation from the preparatory work, and the reviewers' evaluation reports might contain more elaborated articulations in this regard.

Peer review in academic recruitment and promotion is characterized by a high level of intertextuality (see e.g. Chen \& Hyon, 2005). Reviewers' evaluation reports are no exception; reviewers explicitly refer to prior documents in the process, such as policy documents, job advertisements, and candidates' application files. The reviewers in our sample do set out from the advertisements when doing their assessments. We have pointed to several distinctions in the advertisements, and these distinctions create different conditions for the reviewers and the subsequent match-making process. The shorter and the more opaque advertisements are more is the space, responsibility, and power given to the reviewers. This highlights the question of what qualifies a peer, also in view of that prior research has indicated that reviewers' qualifications and own academic profile influence their evaluations (Levander, 2020).

Traditionally, peers have been selected on the basis of their expert knowledge in the subject area or discipline. Based on the selection of reviewers in our sample, there is reason to further examine the boundaries of the subjects or disciplines in the field of education science(s) and what consequences those boundaries might have for the (continuing) formation of the disciplines in the field and the field as whole. The qualification of those who serve as gatekeepers in a discipline is one possible way to undertake such studies (see Sugimoto et al., 2011).

\section{The Professor of Education Science(s) in Late Modernity}

Although there are many different manifestations of disciplinarity (Sugimoto \& Weingart, 2015), in this chapter, we have focused on one particularly interesting index for the emergence and re/formation of a 
disciplinary field-the professorship (Hofstetter \& Schneuwly, 2002). We have demonstrated that the formation of the professorship lies in the intersection of academic values and institutional norms, although an emphasis is put on the latter. We argue that in specific cases presented here the formation of the professorship and education science(s) in late modernity is both contingent and context dependent. Type and traditions of the HEI as well as the academic profile of the department and the maturity of the subject influence what is expected of the holder of the position. In fact, these aspects seem to have a greater influence on the advertisements and the formation of the professorship than the discipline per se. There are indicators that the educational science(s) in the typecasting of professorships in Sweden may be regarded a hybrid structure (see Schriewer \& Keiner, 1992). On the one hand, educational science(s) emerges as a mode of reflection within the education system, on the other hand as a mode of reflection on the education system (see Keiner, 2019).

Irrespective of discipline and HEI, we can see a narrowing of authority for the professor and at the same time an increase of responsibilities. The professors of today need to have a broad competence in a variety of job categories (see Hamann \& Beljean, 2019). It is simply not enough to be an outstanding researcher and excellent teacher, the professor also needs to be a successful fundraiser and appreciated collaborator.

To conclude, in this chapter we have presented findings from a rather small-scale study of professor recruitment in Sweden. The phenomena studied here need further academic attention, preferably by means of full cases in various national contexts and a comparative approach. The framing of this study and the findings pointed out may well serve as an entrance for such future studies.

\section{References}

Angermuller, J. (2017). Academic careers and the valuation of academics: A discursive perspective on status categories and academic salaries in france as compared to the U.S., germany and great britain. Higher Education, 73(6), 963-980. https://doi.org.10.1007/s10734-017-0117-1 
Benner, M. (2009). Kunskapsnation i kris?: politik, pengar och makt i svensk forskning. SISTER.

Chen, R., \& Hyon, S. (2005). Faculty evaluation as a genre system: Negotiating intertextuality and interpersonality. Journal of Applied Linguistics, 2(2), 153-184. https://doi.org/10.1558/japl.2005.2.2.153

Forsberg, E., \& Sundberg, D. (2018). Formeringen av det pedagogiska kunskapsområdet—mot ett forskningsprogram. Pedagogisk forskning i Sverige, 23(5), 5-20.

Foss Lindblad, R., \& Lindblad, S. (2016). Higher education and research in a steady state-on changing premises and practices for educational research in Sweden. Nordic Journal of Studies in Educational Policy, 2016(1), 32371.

Fumasoli, T., Goastellec, G., \& Kehm, B. M. (2015) (red.). Academic work and careers in Europe: Trends, challenges, perspectives (Vol. 12). Springer.

Hamann, J. (2019). The making of professors: Assessment and recognition in academic recruitment. Social Studies of Science, 1-23. https://doi. org/10.1177/0306312719880017

Hamann, J., \& Beljean, S. (2019). Career gatekeeping in cultural fields. American Journal of Cultural Sociology. https://doi.org/10.1057/ s41290-019-00078-7

Hofstetter, R., \& Schneuwly, B. (2002). Institutionalisation of educational sciences and the dynamics of their development. European Educational Research Journal, 1(1), 3-26.

Kaltenbrunner, W., \& de Rijcke, S. (2019). Filling in the gaps: The interpretation of curricula vitae in peer review. Social Studies of Science, 49(6), 863-883. https://doi.org/10.1177/0306312719864164

Keiner, E. (2019). 'Rigour','discipline' and the 'systematic': The cultural construction of educational research identities? European Educational Research Journal, 18(5), 527-545.

Klawitter, M. (2015). Effects of institutional changes on requirements for vacant professorships in Germany. Working Papers in Higher Education Studies, 1(2), 1-19.

Levander, S. (2020). Construction of educational proficiency in academia: Peer review of educational merits in academic recruitment in sweden. Education Inquiry, ahead-of-print(ahead-of-print), 1-18. https://doi.org/ $10.1080 / 20004508.2020 .1843234$

Lindberg, L. (2006/2007). Disciplinen och den dubbla kompetensen. Noteringar i anslutning till ett kvalifikationskrav. Studies in Educational Policy and Educational Philosophy. E-tidskrift 2006:2/2007:1. 
Musselin, C. (2002). Diversity around the profile of the 'good' candidate within French and German universities. Tertiary Education and Management, 8(3), 243-258. https://doi.org/10.1080/13583883.2002.9967082

Musselin, C. (2010). The market for academics. Routledge.

Rosengren, K., \& Öhngren, B. (Eds.). (1997). An evaluation of Swedish research in education. HSFR.

Schriewer, J., \& Keiner, E. (1992). Communication patterns and intellectual traditions in educational sciences: France and Germany. Comparative Education Review, 36(1), 25-51.

SFS. (1993:100/2010:1064). Högskoleförordningen. [Higher education ordinance]. Ministry of Education and Research.

Sugimoto, C. R., Ni, C., Russell, T. G., \& Bychowski, B. (2011). Academic genealogy as an indicator of interdisciplinarity: An examination of dissertation networks in library and information science. Journal of the American Society for Information Science and Technology, 62(9), 1808-1828. https://doi. org/10.1002/asi.21568

Sugimoto, C. R., \& Weingart, S. (2015). The kaleidoscope of disciplinarity. Journal of Documentation, 71(4), 775-794. https://doi.org/10.1108/ jd-06-2014-008

Whitty, G., \& Furlong, J. (2017). Knowledge and the study of education: An international exploration. Symposium Books.

Wojcik, P. R. (2003). Typecasting. Criticism, 45(2), 223-249. https://doi. org/10.1353/crt.2004.0005

Zuckerman, E. (2005). Typecasting and generalism in firm and market: Genrebased career concentration in the feature film industry, 1933-1995. In Jones, C. \& Thornton, P. (Ed.), Transformation in Cultural Industries (Research in the Sociology of Organizations, Vol. 23, pp. 171-214). Emerald Group Publishing Limited. 
Open Access This chapter is licensed under the terms of the Creative Commons Attribution 4.0 International License (http://creativecommons.org/ licenses/by/4.0/), which permits use, sharing, adaptation, distribution and reproduction in any medium or format, as long as you give appropriate credit to the original author(s) and the source, provide a link to the Creative Commons licence and indicate if changes were made.

The images or other third party material in this chapter are included in the chapter's Creative Commons licence, unless indicated otherwise in a credit line to the material. If material is not included in the chapter's Creative Commons licence and your intended use is not permitted by statutory regulation or exceeds the permitted use, you will need to obtain permission directly from the copyright holder.

(c) (i) 